\title{
TERATOMA OF THE TONSIL CAUSING RESPIRATORY OBSTRUCTION IN THE NEWBORN
}

\author{
BY \\ C. D. BAUGH and R. F. O'DONOGHUE \\ From the Royal Infirmary, Preston
}

(RECEIVED FOR PUBLICATION JANUARY 12, 1955)

A teratoma, by definition, is a true tumour or neoplasm composed of multiple tissues of kinds foreign to the part in which it arises. In a series of 82 cases Willis (1953) quotes the following sites of origin: ovary, 50 , and testes 19 , the remainder being epididymal, retroperitoneal, pre-sacral, anterior mediastinal, intrapericardial and cerebral. A careful search of the literature failed to reveal a case where a teratoma had arisen in the tonsillar fossa.

\section{Clinical History}

The case reported here was in a newborn infant. Mrs. O.C., aged 31 years, a third-gravida, after a normal labour of $\mathbf{8}$ hours $\mathbf{5 0}$ minutes, was delivered of a full-term female child weighing $6 \mathrm{lb}$. $9 \mathrm{oz}$. There had been two previous normal pregnancies which had produced normal children and there was nothing relevant to the present case in the family history.

At birth the child was in a state of asphyxia pallida and, although large amounts of mucus were extracted, respiration remained laboured and difficult: a provisional diagnosis of atelectasis was made. Placed in an atmosphere of oxygen and $7^{\circ}{ }_{0} \mathrm{CO}_{2}$ the infant responded slowly and there was some improvement in her colour but breathing was still difficult.

As na further improvement took place it was decided to make a more thorough examination, and on inspection a tumour was seen to be protruding from the posterior surface of the left anterior pillar of the tonsil: the growth was almost entirely obstructing the pharynx. The consultant E.N.T. surgeon of Preston Royal Infirmary thereupon took over the case. He made a tentative diagnosis of sarcoma of the tonsil and took a small biopsy from the tumour.

The infant's condition deteriorated and respiration became almost impossible, but, after emergency enucleation of the tumour mass with a tonsil guillotine breathing was much easier.

After the operation vitamin $K$ and prophylactic penicillin were given but haemorrhage was troublesome. The infant's general condition was too poor to allow the giving of an anaesthetic to secure haemostasis. However, the bleeding was eventually controlled by the use of thrombin drops and the total blood loss was estimated at $4 \mathrm{oz}$.
After the infant's return to the oxygen tent respiration became increasingly rapid, the rectal temperature rose to $105^{\circ} \mathrm{F}$. and the child had cyanotic attacks which were treated with nickethamide. The attacks continued and the baby died some 36 hours after the operation.

Necropsy. On internal examination the main findings were in the respiratory tract. The left tonsil had been removed before death. The fossa was engorged with blood and contained fragments of whitish tissue which were removed. The larynx and trachea were congested and both lungs were enlarged, reddish purple, and their substance showed acute haemorrhagic bronchopneumonia. The right side of the heart was dilated and engorged with blood but otherwise the organ was anatomically normal.

The abdominal organs showed some congestion of the liver but no abnormality elsewhere. The meninges were congested and the brain substance showed no abnormality. The anatomical cause of death was acute haemorrhagic bronchopneumonia.

Pathology. Dr. A. A. Miller reported that the mass removed at operation consisted of one tonsil with two polypi projecting from the external surfaces: the larger polypus measured $15 \times 10 \mathrm{~mm}$., and the smaller one $10 \times 3 \mathrm{~mm}$. The tonsil measured $20 \times 10 \times 15 \mathrm{~mm}$., appeared nodular, and on section showed bony, cartilagenous and other white tissues.

Histological examination showed a disorderly mixture of cartilage, cancellous bone, plain and striated muscle, neuro-epithelium, and renal, cerebral and adipose tissues, together with clumped masses of cells which include lymphocytes, plasma cells, eosinophils and multinucleate giant cells (Figs. 2-4). This was a teratoma (Fig. 1).

Our thanks are due to Mr. Tod and Mr. Corbet, consultant gynaecologists, to Mr. Kersley, consultant E.N.T. surgeon, for permission to publish this case, to Dr. A. A. Miller, consultant pathologist for the postmortem and histological examinations and for looking over the text, and to Mr. F. Ramsden for the photomicrographs.

REFERENCE

Willis, R. A. (1953). Pathology of Tumours, 2nd ed. London. 


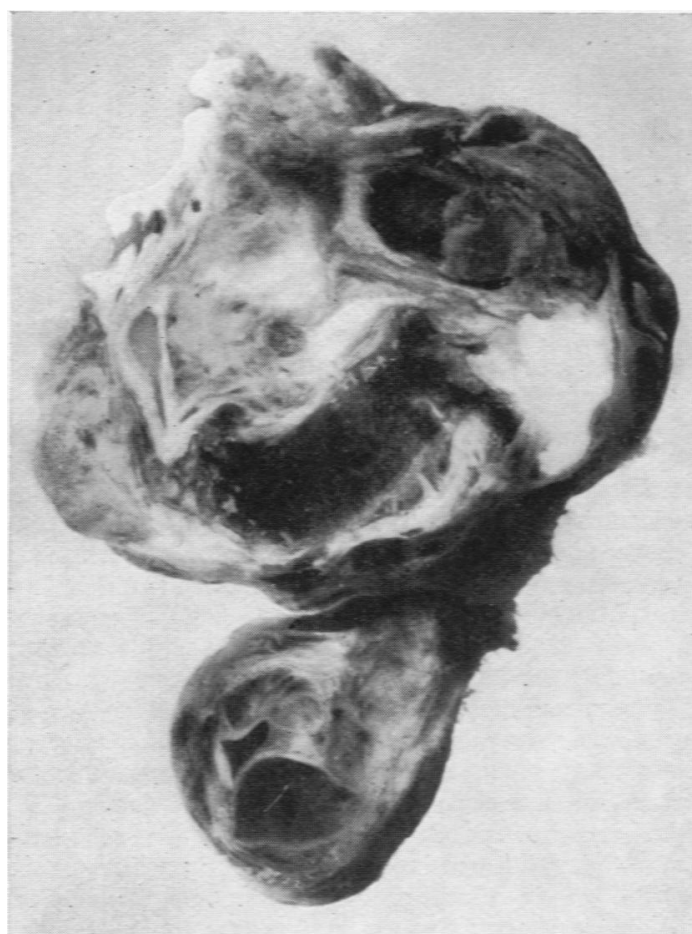

Fig. 1.-Photograph of teratoma of the tonsil. $\times 3$.

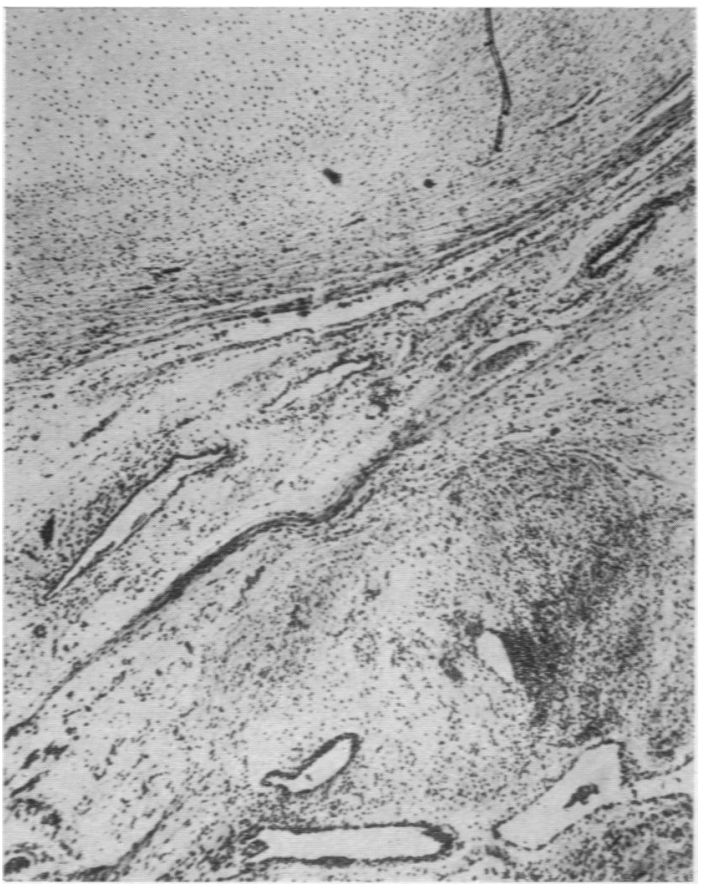

Fig. 2.-Section showing cartilage and connective tissue with epithelial lined spaces. Haematoxylin and cosin. $\times 60$.

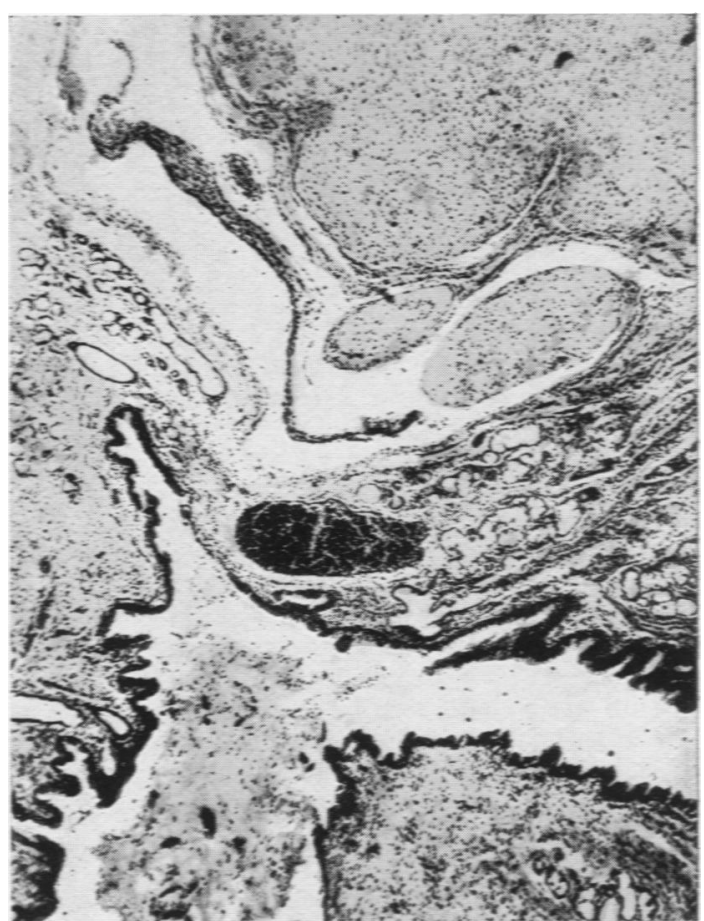

Fig. 3.-Section shows cartilage, mucus glands, hmphoid tissue and neuroepithelium. Haematoxylin and cosin. $\times 60$.

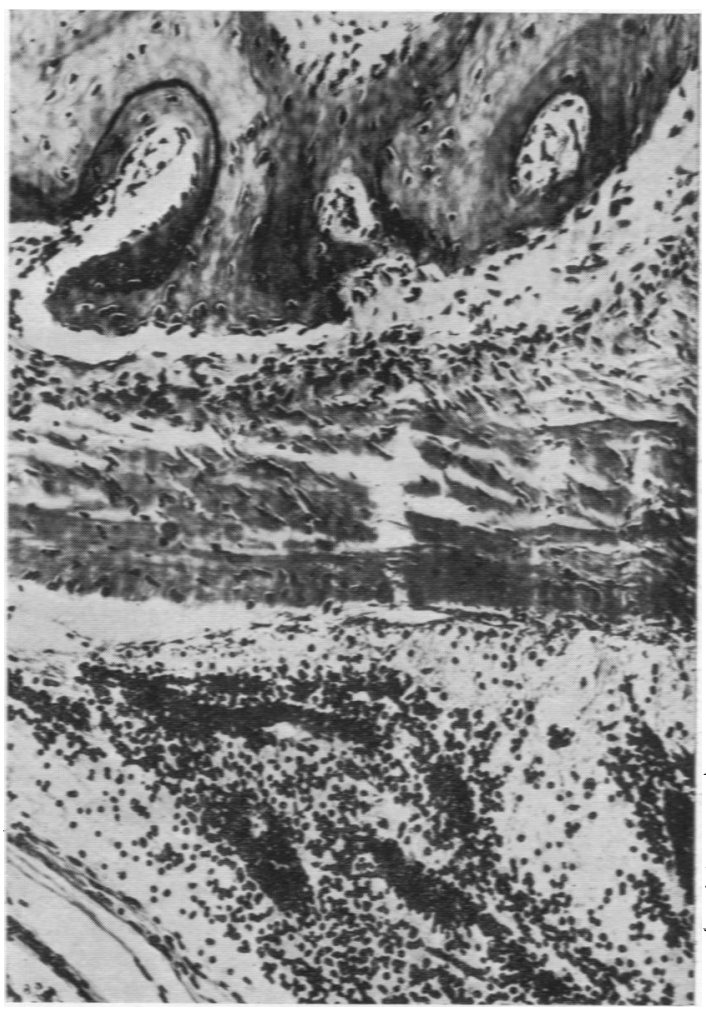

Fig. 4.-A high-power view showing cancellous bone, striated muscle and a mass of lymphocytes. Haematoxylin and cosin. $\times 120$

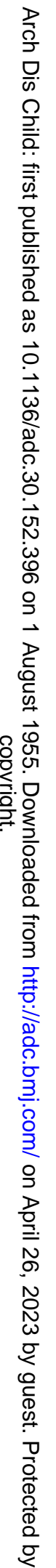

